\title{
Corrosion Inhibition of Mild Steel in Acidic Media by $5^{\prime}$-Phenyl-2', $4^{\prime}$-dihydrospiro[indole-3,3' $3^{\prime}$-pyrazol]-2(1H)-one
}

\author{
M. Jannathul Firdhouse and D. Nalini \\ Department of Chemistry, PSGR Krishnammal College for Women, Tamilnadu, Coimbatore 641004, India \\ Correspondence should be addressed to M. Jannathul Firdhouse; kfirdhouse@yahoo.com
}

Received 7 December 2011; Accepted 24 May 2012

Academic Editor: Sakir Erkoc

Copyright (C) 2013 M. J. Firdhouse and D. Nalini. This is an open access article distributed under the Creative Commons Attribution License, which permits unrestricted use, distribution, and reproduction in any medium, provided the original work is properly cited.

\begin{abstract}
The inhibition effect of $5^{\prime}$-phenyl-2' $4^{\prime}$-dihydrospiro[indole-3, $3^{\prime}$-pyrazol]-2(1H)-one (SPAH) on mild steel corrosion in $1 \mathrm{M} \mathrm{HCl}$ and $0.5 \mathrm{M} \mathrm{H}_{2} \mathrm{SO}_{4}$ has been studied by weight loss, effect of temperature, electrochemical techniques, and quantum chemical studies. The inhibition efficiency increases with increasing concentration of inhibitor but decreases with increase in temperature. The adsorption of inhibitor on mild steel surface has been found to obey Langmuir and Temkin's adsorption isotherm. Potentiostatic polarization results revealed that SPAH acts as mixed type inhibitor. The values of activation energy $\left(E_{a}\right)$, free energy of adsorption $\left(\Delta G^{\circ}\right)$, enthalpy of adsorption $(\Delta H)$, and entropy of adsorption $(\Delta S)$ were calculated. Surface analysis (SEM) was also carried out to establish the mechanism of inhibitor on mild steel corrosion in acid medium. Quantum chemical studies using DFT were employed to explain the experimental results obtained in this study and to further give insight into the inhibition action of SPAH on the mild steel surface.
\end{abstract}

\section{Introduction}

The corrosion of metals remains a worldwide scientific problem as it affects the metallurgical, chemical and oil industries. The increasing interest in the manufacture of hydrochloric acid has created the need for obtaining information on the corrosion resistance of mild steel to hydrochloric acid attack [1]. Acids are widely used in industries such as pickling, cleaning, and decaling. Because of their aggressiveness, inhibitors are used to reduce the rate of dissolution of metals. Compounds containing nitrogen, sulphur, and oxygen have been reported as excellent inhibitors [2-7].

In the present work, electrochemical and nonelectrochemical techniques were used to investigate the inhibition of mild steel corrosion by $5^{\prime}$-phenyl-2' $4^{\prime}$-dihydrospiro[indole$3,3^{\prime}$-pyrazol]-2(1H)-one (see Figure 1 ) with respect to inhibitor concentration and temperature on the inhibitor efficiency (\%) in $1 \mathrm{M}$ hydrochloric acid and $0.5 \mathrm{M}$ sulfuric acid medium. Quantum chemical calculation using DFT was employed to explain the experimental results obtained in this study and to further give insight into the inhibition action of SPAH on the mild steel surface.

\section{Experimental}

Mild steel specimen of the size $(3.5 \times 1.5)-0.5$ was used for measurement of weight loss study. The strips were mechanically polished using $1 / 0,2 / 0,3 / 0$, and $4 / 0$ emery papers and finally degreased with the organic solvent trichloroethylene and dried before use. $1 \mathrm{M} \mathrm{HCl}$ and $0.5 \mathrm{M} \mathrm{H}_{2} \mathrm{SO}_{4}$ solutions were prepared by the dilution of analytical grade $\mathrm{HC1}$ and $\mathrm{H}_{2} \mathrm{SO}_{4}$ with double-distilled water, respectively. The concentration range of inhibitor used was $(1 \mathrm{ppm}, 3 \mathrm{ppm}$, $5 \mathrm{ppm}, 7 \mathrm{ppm}$, and $9 \mathrm{ppm}$ ) in both the acids. The compound has been synthesized in 3 steps. The structural formula of the investigated compound is given below.

Weight loss measurements were carried out by weighing the specimens in triplicate before and after immersion in $100 \mathrm{~mL}$ acid solution for 3 hours in the absence and presence of inhibitor for various concentrations.

Electrochemical measurements were carried out in a glass cell with a capacity of $100 \mathrm{~mL}$. A platinum electrode and a saturated calomel electrode were used as a counter electrode and reference electrode, respectively. The mild steel electrode was then placed in the test solution (uninhibited 


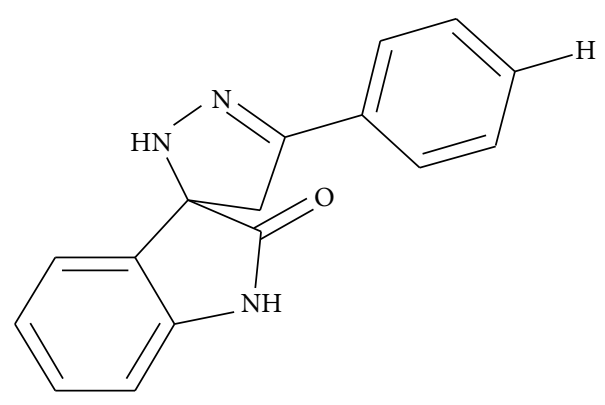

(a)

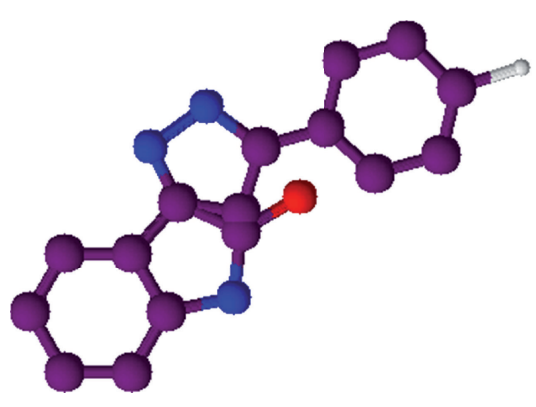

(b)

FIgURe 1: Molecular structure of $5^{\prime}$-phenyl-2 ${ }^{\prime}, 4^{\prime}$-dihydrospiro[indole-3,3' ${ }^{\prime}$-pyrazol]-2(1H)-one.

TABLE 1: Inhibition efficiencies of SPAH for the corrosion of mild steel obtained by weight loss measurements.

\begin{tabular}{|c|c|c|c|c|c|}
\hline Name of the inhibitor & $\begin{array}{c}\text { Inhibitor } \\
\text { concentration (ppm) }\end{array}$ & Weight loss (g) & Corrosion rate (mpy) & $\begin{array}{l}\text { Inhibition efficiency } \\
(\%)\end{array}$ & Surface coverage $(\theta)$ \\
\hline \multirow{6}{*}{$1 \mathrm{M} \mathrm{HCl}$} & Blank & 0.0863 & 1227 & & \\
\hline & 1 & 0.0549 & 780 & 36.4 & 0.3638 \\
\hline & 3 & 0.0447 & 635 & 48.4 & 0.4840 \\
\hline & 5 & 0.0361 & 513 & 58.2 & 0.5816 \\
\hline & 7 & 0.035 & 497 & 64.7 & 0.6465 \\
\hline & 9 & 0.0261 & 371 & 69.8 & 0.6975 \\
\hline \multirow{6}{*}{$0.5 \mathrm{M} \mathrm{H}_{2} \mathrm{SO}_{4}$} & Blank & 0.1611 & 2290 & & \\
\hline & 1 & 0.0938 & 1333 & 41.8 & 0.4177 \\
\hline & 3 & 0.0623 & 885 & 61.3 & 0.6132 \\
\hline & 5 & 0.0424 & 603 & 73.7 & 0.7368 \\
\hline & 7 & 0.0385 & 547 & 76.1 & 0.7610 \\
\hline & 9 & 0.0342 & 486 & 78.8 & 0.7877 \\
\hline
\end{tabular}

and inhibited solutions) for 10-15 minutes before electrochemical measurements. Electrochemical impedance spectroscopy (EIS) and Tafel polarization were conducted in an electrochemical measurement unit (model 1280 B Solartron, UK). The EIS measurement was made at corrosion potentials over a frequency range of $10 \mathrm{KHz}$ to $0.01 \mathrm{~Hz}$ with signal amplitude of $10 \mathrm{mV}$. The Tafel polarization measurements were made after EIS for a potential range of $-200 \mathrm{mV}$ to $+200 \mathrm{mV}$ with respect to open circuit potential at a scan rate of $1 \mathrm{mV} / \mathrm{sec}$.

The specimen used for surface morphological examination was immersed in acid $(1 \mathrm{M} \mathrm{HCl})$ containing higher concentration (9 ppm) for the inhibitor and blank for 3 hours. Then removed, rinsed quickly with distilled water, and dried. The analysis was performed on HITACHI model S-3000 H SEM. The IR spectra of the inhibitors were recorded on a Bruker Optik GmbH model no-Tensor 27 Spectrophotometer in the range $4000-400 \mathrm{~cm}^{-1}$ using $\mathrm{KBr}$ disc technique.

$B 3 L Y P$, a version of the DFT method that uses Becke's three parameter functional (B3) and includes a mixture of HF with DFT exchange terms associated with the gradient corrected correlation functional of Lee, Yang, and Parr (LYP) [8], was used in this paper to carry out quantum calculations. Then, full geometry optimization together with the vibrational analysis of the optimized structures of the inhibitor was carried out at the B3LYP/6-31G (d) level of theory using Spartan'06 V112 program package [9] in order to determine whether they correspond to a maximum or a minimum in the potential energy curve.

\section{Results and Discussion}

3.1. Weight Loss Measurements. The inhibition efficiency with different concentration of the inhibitor (SPAH) on mild steel has been evaluated by weight loss measurements and the results are given in Table 1. In all cases, the value of IE increases with increase in inhibitor concentration, suggesting an increase of the number of molecules adsorbed on mild steel surface [7], blocking the active sites of acid attack which protects the metal from corrosion. The maximum efficiency of SPAH is $69.8 \%$ and $78.8 \%$ in $1 \mathrm{M} \mathrm{HCl}$ and $0.5 \mathrm{M} \mathrm{H}_{2} \mathrm{SO}_{4}$ respectively. The corrosion inhibition of the compound is due to the presence of heteroatoms $(\mathrm{O}, \mathrm{N}, \mathrm{S})$ and aryl group [10].

3.2. Effect of Temperature. The effect of temperature on the performance of the SPAH (Table 2) clearly indicates that the corrosion rate increases with increasing temperature. Adsorption and desorption of inhibitor molecules continuously occur at the metal surface and an equilibrium exists between two processes at a particular temperature. 
TABLE 2: Inhibition efficiencies of inhibitor for the corrosion of mild steel obtained by weight loss measurements at various temperatures.

\begin{tabular}{|c|c|c|c|c|c|}
\hline \multirow{2}{*}{$\begin{array}{l}\text { Concentration of the } \\
\text { inhibitor (ppm) }\end{array}$} & \multirow{2}{*}{ Temperature (K) } & \multicolumn{2}{|c|}{$1 \mathrm{M} \mathrm{HCl}$} & \multicolumn{2}{|c|}{$0.5 \mathrm{M} \mathrm{H}_{2} \mathrm{SO}_{4}$} \\
\hline & & $\begin{array}{l}\text { Corrosion rate } \\
(\mathrm{mpy})\end{array}$ & $\begin{array}{c}\text { Inhibition efficiency } \\
(\%)\end{array}$ & $\begin{array}{c}\text { Corrosion rate } \\
\text { (mpy) }\end{array}$ & $\begin{array}{c}\text { Inhibition efficiency } \\
(\%)\end{array}$ \\
\hline \multirow{5}{*}{1} & 303 & 930 & 32.7 & 887 & 43.5 \\
\hline & 313 & 1927 & 29.4 & 1151 & 37.2 \\
\hline & 323 & 2294 & 27.1 & 5756 & 28.6 \\
\hline & 333 & 5211 & 16.0 & 9858 & 20.3 \\
\hline & 343 & 10353 & 12.2 & 18019 & 15.0 \\
\hline \multirow{5}{*}{3} & 303 & 759 & 54.1 & 733 & 53.3 \\
\hline & 313 & 1595 & 41.6 & 785 & 50.0 \\
\hline & 323 & 1902 & 39.6 & 3795 & 48.9 \\
\hline & 333 & 4375 & 28.8 & 7411 & 40.1 \\
\hline & 343 & 9611 & 18.5 & 14975 & 29.4 \\
\hline \multirow{5}{*}{5} & 303 & 623 & 54.9 & 452 & 71.2 \\
\hline & 313 & 1296 & 52.5 & 631 & 65.6 \\
\hline & 323 & 1535 & 51.2 & 3087 & 58.4 \\
\hline & 333 & 3411 & 45.0 & 5876 & 52.5 \\
\hline & 343 & 8613 & 27.0 & 13380 & 36.9 \\
\hline \multirow{5}{*}{7} & 303 & 529 & 61.7 & 409 & 73.9 \\
\hline & 313 & 1117 & 59.1 & 588 & 67.9 \\
\hline & 323 & 1441 & 54.2 & 2695 & 63.7 \\
\hline & 333 & 2857 & 50.5 & 5475 & 55.7 \\
\hline & 343 & 7334 & 37.8 & 12502 & 41.1 \\
\hline \multirow{5}{*}{9} & 303 & 461 & 66.7 & 341 & 78.3 \\
\hline & 313 & 1015 & 62.8 & 452 & 75.3 \\
\hline & 323 & 1237 & 60.7 & 2072 & 72.1 \\
\hline & 333 & 2499 & 59.7 & 4827 & 61.0 \\
\hline & 343 & 5543 & 53.0 & 10114 & 52.3 \\
\hline
\end{tabular}

TABLE 3: Activation energies $\left(E_{\mathrm{a}}\right)$ and free energy of adsorption $\left(\Delta G^{\circ}\right)$ for the corrosion of mild steel in $1 \mathrm{M} \mathrm{HCl}$ and $1 \mathrm{M} \mathrm{H}_{2} \mathrm{SO}_{4}$.

\begin{tabular}{|c|c|c|c|c|c|c|c|c|c|c|c|c|}
\hline \multirow{3}{*}{ Name of the inhibitor } & & & \multicolumn{10}{|c|}{$-\Delta G^{\circ}$ at various temperatures $\left(\mathrm{kJ} \mathrm{mol}^{-1}\right)$} \\
\hline & \multicolumn{2}{|c|}{$E_{\mathrm{a}}\left(\mathrm{kJ} \mathrm{mol}^{-1}\right)$} & \multicolumn{5}{|c|}{$1 \mathrm{M} \mathrm{HCl}$} & \multicolumn{5}{|c|}{$0.5 \mathrm{M} \mathrm{H}_{2} \mathrm{SO}_{4}$} \\
\hline & $\mathrm{HCl}$ & $\mathrm{H}_{2} \mathrm{SO}_{4}$ & $303 \mathrm{~K}$ & $313 \mathrm{~K}$ & $323 \mathrm{~K}$ & $333 \mathrm{~K}$ & $343 \mathrm{~K}$ & $303 \mathrm{~K}$ & $313 \mathrm{~K}$ & $323 \mathrm{~K}$ & $333 \mathrm{~K}$ & $343 \mathrm{~K}$ \\
\hline Blank & 26.07 & 58.97 & - & - & - & - & - & - & - & - & - & - \\
\hline SPAH & 48.84 & 76.02 & 6.32 & 6.09 & 6.05 & 6.12 & 5.52 & 7.80 & 7.64 & 7.43 & 6.27 & 5.45 \\
\hline
\end{tabular}

With increase of temperature, the equilibrium between the adsorption and desorption processes is shifted to a higher desorption rate than adsorption until equilibrium is again established at a different value of equilibrium constant. It explains the lower inhibition efficiency at higher temperature.

The activation energies were calculated from the slopes of Arrhenius plots (Figure 2) for uninhibited and inhibited systems. It is apparent from the values of $E_{a}$ (Table 3 ) that the activation energy is higher in the presence of inhibitor, suggesting that higher energy barrier for the corrosion process in the inhibited solution and also implies [11] a slow reaction.

3.3. Thermodynamic Parameters. The thermodynamic functions such as the free energy of adsorption $\left(\Delta G^{\circ}\right)$, the heat of adsorption $\left(\Delta H^{\circ}\right)$, and the entropy of adsorption $\left(\Delta S^{\circ}\right)$ are very important to explain the adsorption phenomenon of inhibitor molecule. The free energy adsorption $\left(\Delta G^{\circ}\right)$ were calculated using the following equation,

$$
-\Delta G^{\circ}=2.303 \times R T\left\{1.74+\log \left[\frac{\theta}{1-\theta}\right]-\log C\right\} .
$$

The negative values [12] of $\Delta G^{\circ}$ in all cases ensure the spontaneity of the adsorption process and stability of the adsorbed layer on the metal surface. Enthalpy of adsorption $\left(\Delta H^{\circ}\right)$ and enthalpy of adsorption $\left(\Delta S^{\circ}\right)$ were obtained from intercept and slope of the plot $-\Delta G^{\circ}$ against $T$ depicted in (Figure 3 ) and are given in Table 4 . The negative sign of the $\Delta H^{\circ}$ reflects the exothermic nature of the mild steel 
TABLE 4: Some thermodynamic parameters $\Delta S^{\circ}$ and $\Delta H^{\circ}$ for the corrosion of mild steel in $1 \mathrm{M} \mathrm{HCl}$ and $0.5 \mathrm{M} \mathrm{H}_{2} \mathrm{SO}_{4}$.

\begin{tabular}{|c|c|c|c|c|}
\hline \multirow{2}{*}{ Name of the inhibitor } & \multicolumn{2}{|c|}{$\Delta S^{\circ}(\mathrm{J} / \mathrm{mol} / \mathrm{K})$} & \multicolumn{2}{|c|}{$-\Delta H^{\circ}(\mathrm{kJ} / \mathrm{mol})$} \\
\hline & $1 \mathrm{M} \mathrm{HCl}$ & $0.5 \mathrm{M} \mathrm{H}_{2} \mathrm{SO}_{4}$ & $1 \mathrm{M} \mathrm{HCl}$ & $0.5 \mathrm{M} \mathrm{H}_{2} \mathrm{SO}_{4}$ \\
\hline SPAH & 15.7 & 46.17 & 60.7 & 26.52 \\
\hline
\end{tabular}

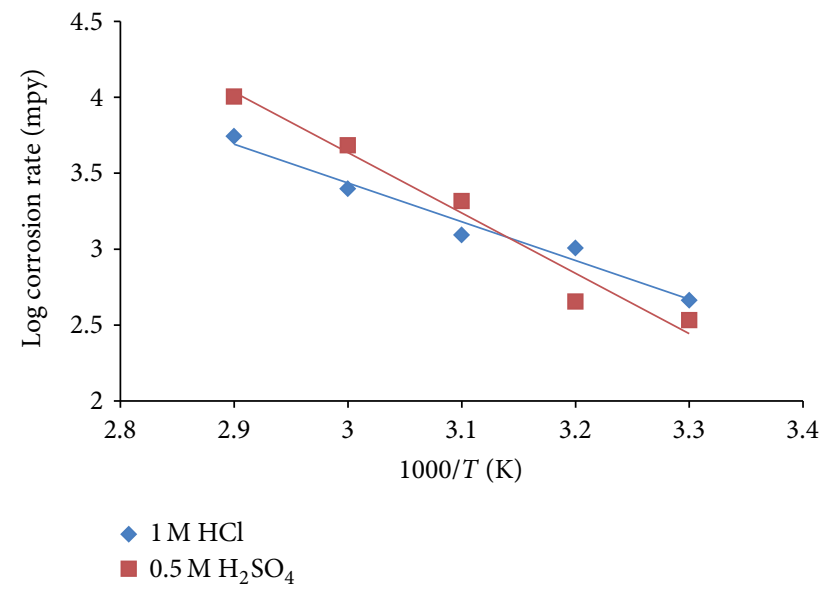

FIGURE 2: Arrhenius plot for the corrosion of mild steel.

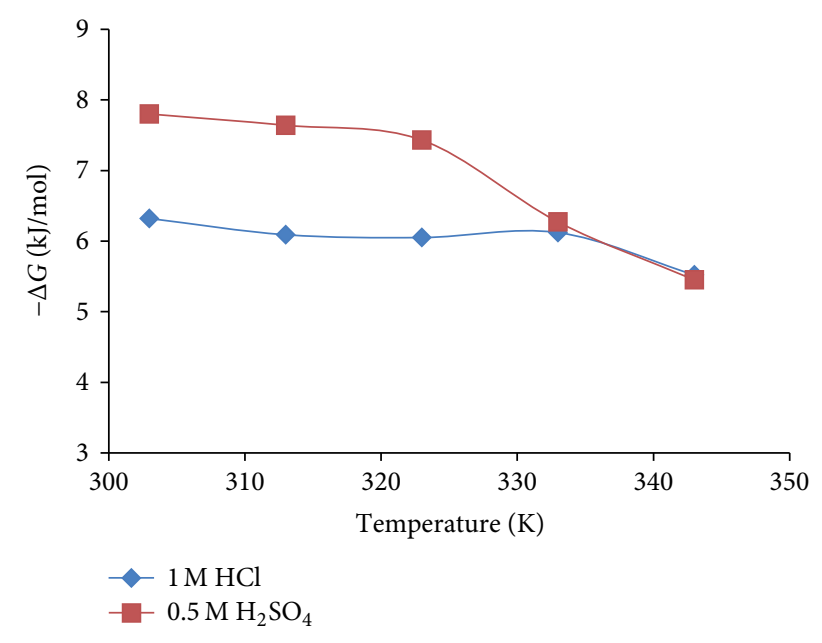

FIGURE 3: Free energy of adsorption of SPAH in in $1 \mathrm{M} \mathrm{HCl}$ and $0.5 \mathrm{M} \mathrm{H}_{2} \mathrm{SO}_{4}$ in the presence of SPAH $1 \mathrm{M} \mathrm{HCl}$ and $0.5 \mathrm{M} \mathrm{H}_{2} \mathrm{SO}_{4}$.

adsorption process in the presence of SPAH in both the acidic media [13]. The values of $\Delta H^{\circ}$ obtained in this study are low, confirming that the inhibitors were physically adsorbed onto the mild steel surface. The $\Delta S^{\circ}$ values in the presence of these three inhibitors are positive, indicating that an increase in disordering takes place in going from reactants to the metal adsorbed species reaction complex [14].

3.4. Adsorption Isotherm. Figure (4) shows the plot of $C / \theta$ Versus $C$ and the expected linear relationship is obtained

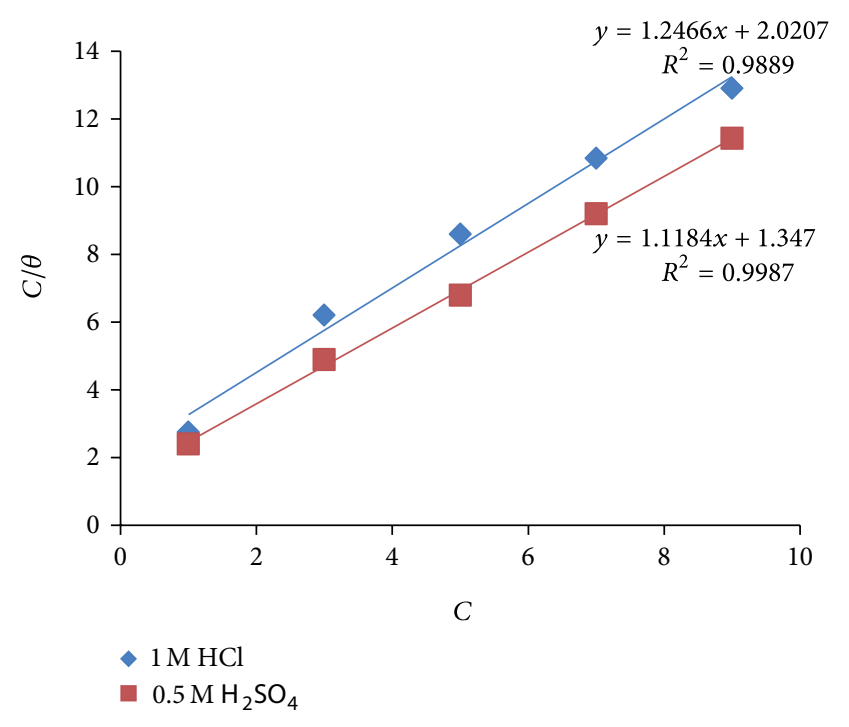

FIGURE 4: Langmuir adsorption isotherm for inhibitor in $1 \mathrm{M} \mathrm{HCl}$ and $0.5 \mathrm{M} \mathrm{H}_{2} \mathrm{SO}_{4}$.

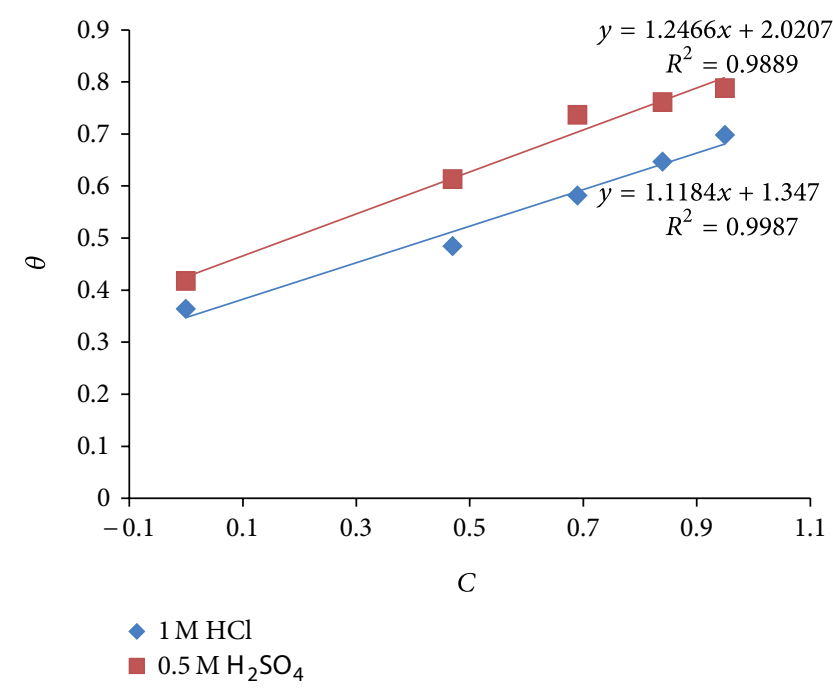

FIGURE 5: Temkin adsorption isotherm for inhibitor in $1 \mathrm{M} \mathrm{HCl}$ and $0.5 \mathrm{M} \mathrm{H}_{2} \mathrm{SO}_{4}$.

with $R^{2}$ value for SPAH. The results indicate that the $R^{2}$ values were very close to unity indicating strong adherence of adsorption which fits to the Langmuir adsorption isotherm. The Temkin adsorption isotherm was found to best describe the experimental results for SPAH adsorption on the clouding mild steel surface at $303 \mathrm{~K}$ studied, with $R^{2}$ values obtained from the plot of $\theta$ as a function of $\log C$ (Figure 5). 


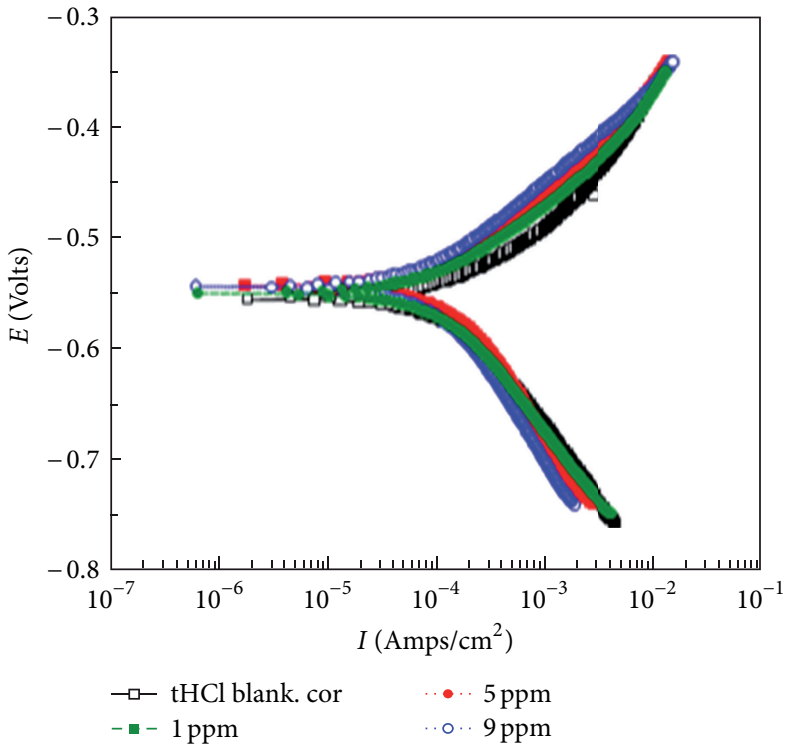

(a)

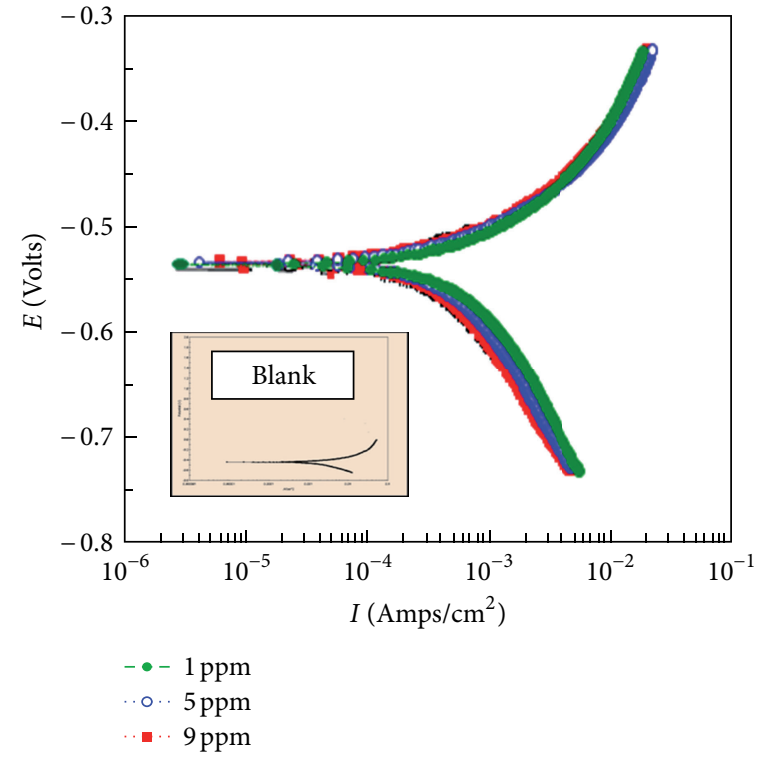

(b)

Figure 6: Polarisation curves of SPAH for mild steel in (a) $1 \mathrm{M} \mathrm{HCl}$ and (b) $0.5 \mathrm{M} \mathrm{H}_{2} \mathrm{SO}_{4}$.

TABLE 5: Potentiodynamic polarization parameters for the corrosion of mild steel in $1 \mathrm{M} \mathrm{HCl}$ and $0.5 \mathrm{M} \mathrm{H}_{2} \mathrm{SO}_{4}$ with and without inhibitor.

\begin{tabular}{|c|c|c|c|c|c|c|}
\hline $\begin{array}{l}\text { Name of the } \\
\text { inhibitor }\end{array}$ & $\begin{array}{c}\text { Inhibitor } \\
\text { concentration } \\
(\mathrm{ppm})\end{array}$ & $\begin{array}{c}I_{\text {corr }} \\
\left(\mu \mathrm{A} / \mathrm{cm}^{2}\right) \times 10^{2}\end{array}$ & $\begin{array}{c}E_{\text {corr }} \\
(\mathrm{mV} \text { versus SCE })\end{array}$ & $\begin{array}{c}\beta_{\mathrm{c}} \\
(\mathrm{mV} / \mathrm{dec})\end{array}$ & $\begin{array}{c}\beta_{\mathrm{a}} \\
(\mathrm{mV} / \mathrm{dec})\end{array}$ & $\begin{array}{c}\text { Inhibition } \\
\text { efficiency (\%) }\end{array}$ \\
\hline \multirow[t]{2}{*}{$1 \mathrm{M} \mathrm{HCl}$} & Blank & 1.6759 & -555.68 & 149.91 & 89.961 & \\
\hline & 1 & 1.3797 & -543.91 & 157.94 & 92.412 & 17.67 \\
\hline \multirow[t]{2}{*}{ SPAH } & 5 & 1.1145 & -550.84 & 130.20 & 83.362 & 33.49 \\
\hline & 9 & 9.5813 & -544.70 & 150.50 & 90.651 & 42.82 \\
\hline \multirow[t]{2}{*}{$0.5 \mathrm{M} \mathrm{H}_{2} \mathrm{SO}_{4}$} & Blank & 16.99 & -444.62 & 113.48 & 231.18 & \\
\hline & 1 & 9.1947 & -536.55 & 273.62 & 123.04 & 45.88 \\
\hline \multirow[t]{2}{*}{ SPAH } & 5 & 6.2370 & -534.52 & 249.93 & 101.00 & 63.29 \\
\hline & 9 & 5.6636 & -534.78 & 229.22 & 97.09 & 66.66 \\
\hline
\end{tabular}

3.5. Potentiodynamic Polarization Studies. The electrochemical parameters such as corrosion potential $\left(E_{\text {corr }}\right)$, corrosion current $\left(I_{\text {corr }}\right)$, and Tafel slope $\left(\beta_{c}\right.$ and $\left.\beta_{a}\right)$ derived from polarization curves (Figure 6) are listed in Table 5. Inspection of tables reveals that the addition of SPAH shifted the $E_{\text {corr }}$ to less negative values and no definite trend was observed in the shift of $E_{\text {corr }}$ values in the presence of various concentrations of inhibitor. The values of $I_{\text {corr }}$ of mild steel in the inhibited solution were smaller than those for the inhibitor free solution. The decrease of corrosion current may be explained by the action of inhibitor on both cathodic and anodic reactions [15]. In the case of SPAH in $0.5 \mathrm{M} \mathrm{H}_{2} \mathrm{SO}_{4}$ and $1 \mathrm{M} \mathrm{HCl}$ medium, the anodic $\left(\beta_{a}\right)$ Tafel slope value and the cathodic $\left(\beta_{c}\right)$ Tafel slope value were slightly affected and indicate that the compound behave as a mixed type inhibitor.

3.6. Impedance Measurements. The corrosion kinetic parameters such as charge transfer resistance $\left(R_{\mathrm{ct}}\right)$ and double layer capacitance $\left(C_{\mathrm{dl}}\right)$ have been derived from Nyquist plot and percentages of IE are given in Table 6. The existence of semicircle in the Nyquist plot (Figure 7) indicates that the corrosion of inhibitors is mainly controlled by a charge transfer process [16]. The presence of inhibitors enhances the values of $R_{\mathrm{ct}}$. This indicates that the inhibitors do not alter the electrochemical reaction responsible for corrosion but inhibit corrosion primarily through their adsorption onto the metal surface. The decrease in $C_{\mathrm{dl}}$ values could be attributed to the adsorption of the inhibitor molecule at the metal surface [17].

The results obtained from impedance show a similar trend for the tested compound as those obtained from potentiodynamic polarization and weight loss measurement but yield different value of IE due to different experimental conditions.

3.7. SEM Analysis. SEM photograph of the metal sample in the presence and absence of inhibitor are shown in Figures $8(\mathrm{a})$ and $8(\mathrm{~b})$. The inhibited metal surface is smoother 
TABLE 6: Impedance parameters for the corrosion of mild steel in $1 \mathrm{M} \mathrm{HCl}$ and $0.5 \mathrm{M} \mathrm{H}_{2} \mathrm{SO}_{4}$ with and without inhibitor.

\begin{tabular}{lccccccc}
\hline $\begin{array}{l}\text { Name of the } \\
\text { inhibitor }\end{array}$ & $\begin{array}{c}\text { Inhibitor } \\
\text { concentration } \\
(\mathrm{ppm})\end{array}$ & $\begin{array}{c}R_{\mathrm{ct}} \\
(\mathrm{ohms})\end{array}$ & $\begin{array}{c}1 \mathrm{M} \mathrm{HCl} \\
\left(\text { farads) } \times 10^{-5}\right.\end{array}$ & $\begin{array}{c}C_{\mathrm{dl}} \\
\text { efficiency } \\
(\%)\end{array}$ & $\begin{array}{c}R_{\mathrm{ct}} \\
(\mathrm{ohms})\end{array}$ & $\begin{array}{c}0.5 \mathrm{M} \mathrm{H}_{2} \mathrm{SO}_{4} \\
(\text { farads }) \times 10^{-5}\end{array}$ & $\begin{array}{c}\text { Inhibition } \\
\text { efficiency } \\
(\%)\end{array}$ \\
\hline & Blank & 136.53 & 1.1717 & & 11.32 & 6.2030 \\
SPAH & 1 & 154.83 & 2.1938 & 11.8 & 37.49 & 2.8020 & 69.8 \\
& 5 & 168.33 & 2.7641 & 18.9 & 55.50 & 2.3966 & 79.6 \\
\hline
\end{tabular}

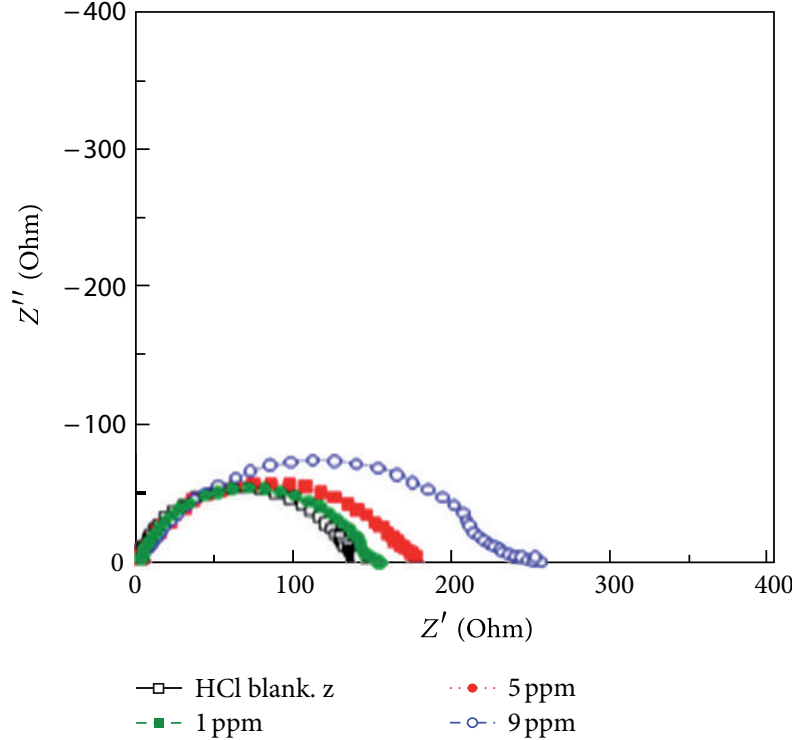

(a)

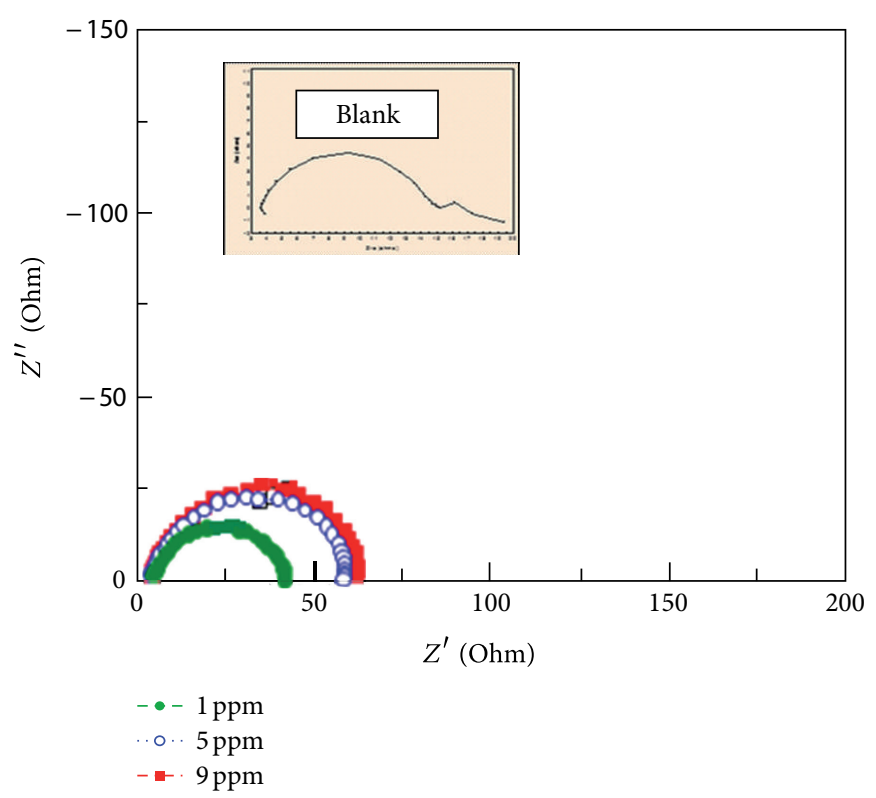

(b)

FIGURE 7: Nyquist plots of SPAH for mild steel in (a) $1 \mathrm{M} \mathrm{HCl}$ and (b) $0.5 \mathrm{M} \mathrm{H}_{2} \mathrm{SO}_{4}$.

than the uninhibited surface indicating a protective layer of adsorbed inhibitor preventing acid attack.

3.8. Quantum Chemical Studies. The calculated values of the quantum chemical parameters obtained using the Hartreefock- Density functional theory (HF-DFT) by Becke 3 Lee, Yang, and Parr (B3LYP) method with $6-31 \mathrm{G}^{*}$ basis set of Spartan'06 V112 program are presented in Table 7. The frontier molecular orbital energies (i.e., $E_{\mathrm{HOMO}}$ and $E_{\mathrm{LUMO}}$ ) are significant parameters for the prediction of the reactivity of a chemical species. The $E_{\mathrm{HOMO}}$ is often associated with the electron donating ability of a molecule. Therefore, increasing values of $E_{\mathrm{HOMO}}$ indicate higher tendency for the donation of electron(s) to the appropriate acceptor molecule with low energy and empty molecular orbital. The increasing values of $E_{\text {HOMO }}$ facilitate the adsorption of the inhibitor. Consequently, the inhibition efficiency of the inhibitor would be enhanced by improving the transport process through the adsorbed layer $[18,19]$.

The negative sign of the $E_{\mathrm{HOMO}}$ value obtained and other thermodynamic parameters indicates that the data obtained supports physical adsorption mechanism. Literature reveals
TABLE 7: Quantum chemical parameters obtained by Spartan'06.

\begin{tabular}{lc}
\hline Quantum chemical parameters & SPAH \\
\hline Molecular formula & $\mathrm{C}_{16} \mathrm{H}_{13} \mathrm{~N}_{3} \mathrm{O}$ \\
Total energy $(\mathrm{a} . \mathrm{u})$ & -856.984 \\
$E_{\mathrm{HOMO}}(\mathrm{eV})$ & -5.32 \\
$E_{\mathrm{LUMO}}(\mathrm{eV})$ & -0.92 \\
$\Delta E\left(E_{\mathrm{LUMO}}-E_{\mathrm{HOMO}}\right)(\mathrm{eV})$ & 4.4 \\
Dipole moment $(\mu)(\mathrm{D})$ & 4.68 \\
Molecular weight $(\mathrm{amu})$ & 263.300 \\
Polarizability & 62.02 \\
Cosmo area $\left(\AA^{2}\right)$ & 281.24 \\
Cosmo volume $\left(\AA^{3}\right)$ & 267.31 \\
Global hardness $(\eta)$ & 2.20 \\
Global softness $(\sigma)$ & 0.45 \\
Electronegativity $(\chi)$ & 3.12 \\
\hline
\end{tabular}

that a larger value of the energy gap indicates low reactivity to a chemical species because the energy gap is related to the softness or hardness of a molecule [20,21]. A soft molecule is 


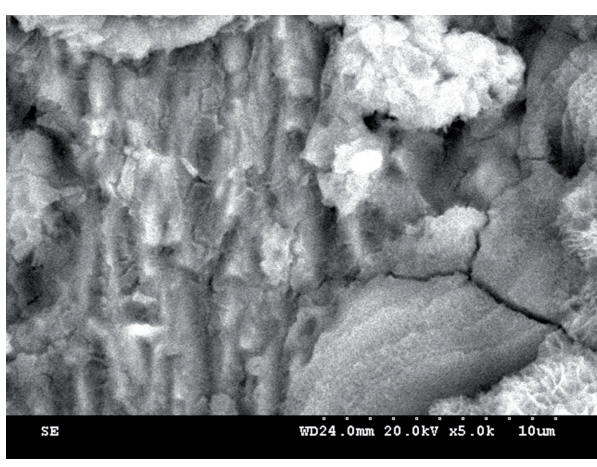

(a)

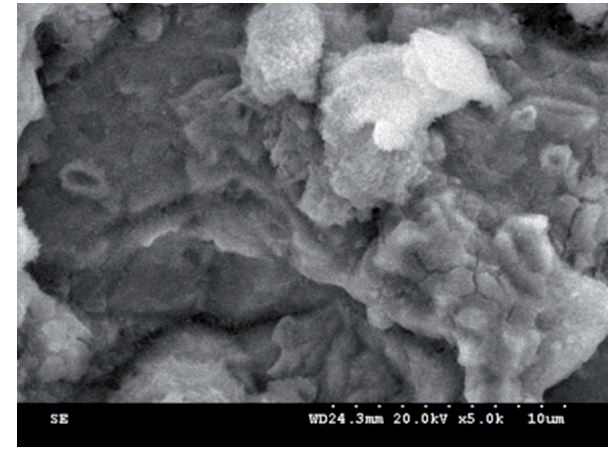

(b)

FIGURE 8: (a) SEM micrographs of $1 \mathrm{M} \mathrm{HCl}$, (b) $1 \mathrm{M} \mathrm{HCl}+\mathrm{SPAH}$.

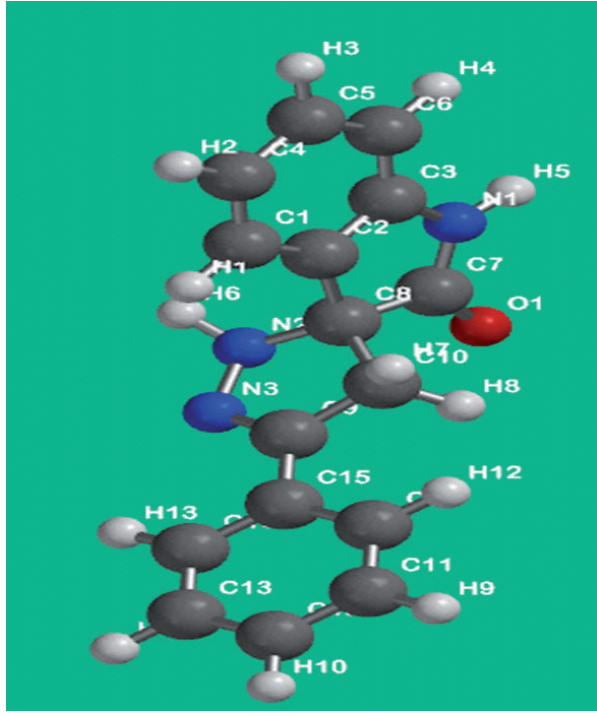

(a)

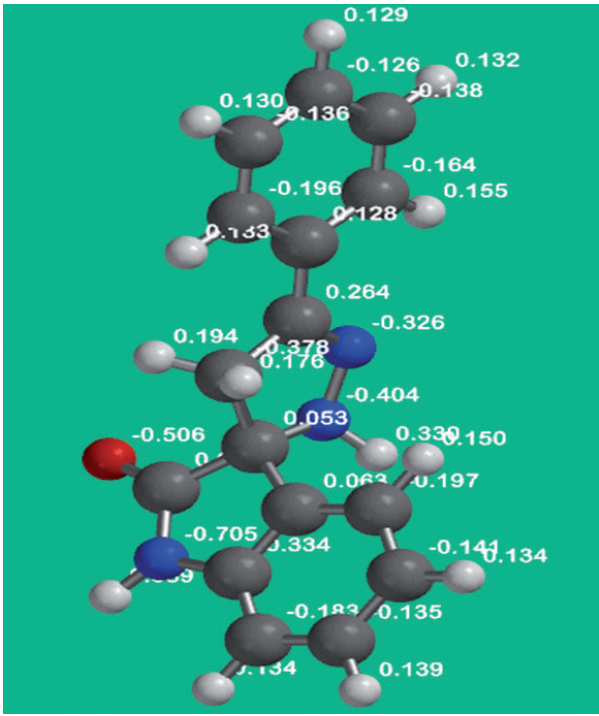

(b)

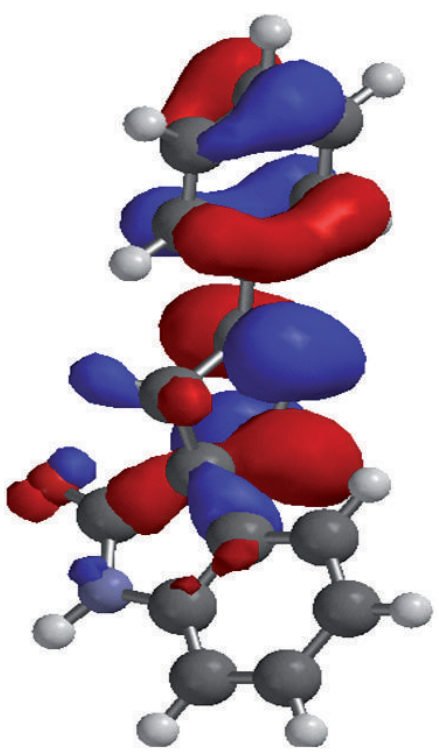

(c)

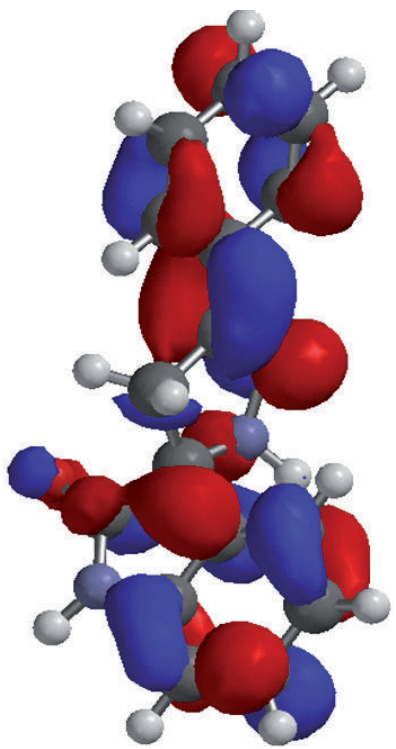

(d)

FIGURE 9: (a-d) Optimised Geometry, Mulliken charges, HOMO and LUMO density distribution of SPAH. 
more reactive than a hard molecule because a hard molecule has a larger energy gap. This indicates that both the values of the energy gap, $\Delta E=E_{\mathrm{LUMO}}-E_{\mathrm{HOMO}}$ as well as that of the dipole moment, $\mu$ favour SPAH implying its effectiveness as a corrosion inhibitor. There is a general consensus by several authors that the more negatively charged heteroatom can be adsorbed on the metal surface through the donoracceptor type reaction [22, 23]. Moreover, a smaller energy gap, $\Delta E\left(E_{\text {LUMO }}-E_{\text {HOMO }}\right)$, a higher molecular weight, low electronegativity, high polarizability, higher area, and volume enhances effective adsorption of spiropyrazoline on the mild steel surface thus decreasing the corrosion rate of the mild steel (see Figure 9).

\section{Conclusion}

The main conclusions drawn from this study are SPAH efficiently inhibits the corrosion of mild steel in $1 \mathrm{M} \mathrm{HCl}$ and $0.5 \mathrm{M} \mathrm{H}_{2} \mathrm{SO}_{4}$ media. SPAH behaves as mixed type inhibitor. Adsorption of SPAH on the surface of mild steel from $1 \mathrm{M} \mathrm{HCl}$ and $0.5 \mathrm{M} \mathrm{H}_{2} \mathrm{SO}_{4}$ obey's Langmuir and Temkin's adsorption isotherm. Reduction in the values of $I_{\text {corr }}$ and $C_{\mathrm{dl}}$ in the presence of an inhibitor has been dealt. The inhibition efficiency of SPAH increases with increasing the inhibitor concentration. On increasing the temperature, the corrosion rate increases. Protective film formation against the acid attack is confirmed by SEM. Comparison between the theoretical findings satisfactorily correlates with experimental results and validate the method employed here.

\section{Acknowledgments}

The authors thank the Director of ICP centre, CECRI, Karaikudi, for providing the facilities of electrochemical studies and SEM facilities and Dr. Jeyakanthan, Head of the Department of Bioinformatics, Alagappa University, Karaikudi, for providing the Spartan software facilities, and Management and Principal, PSGR Krishnammal college for Women, Coimbatore for providing necessary facilities and encouragement.

\section{References}

[1] O. James, N. C. Oforka, and O. K. Abiola, "Inhibition of acid corrosion of mild steel by pyridoxal and pyridoxol hydrochlorides," International Journal of Electrochemical Science, vol. 2, pp. 278-284, 2007.

[2] M. Lagrenée, B. Mernari, M. Bouanis, M. Traisnel, and F. Bentiss, "Study of the mechanism and inhibiting efficiency of 3,5-bis(4-methylthiophenyl)-4H-1,2,4-triazole on mild steel corrosion in acidic media," Corrosion Science, vol. 44, no. 3, pp. 573-588, 2002.

[3] M. A. Quraishi and R. Sardar, "Aromatic triazoles as corrosion inhibitors for mild steel in acidic environments," Corrosion, vol. 58, no. 9, pp. 748-755, 2002.

[4] A. K. Singh and M. A. Quraishi, "The effect of some bisthiadiazole derivatives on the corrosion of mild steel in hydrochloric acid," Corrosion Science, vol. 52, no. 4, pp. 1373-1385, 2010 .
[5] M. A. Quraishi and F. A. Ansari, "Corrosion inhibition by fatty acid triazoles for mild steel in formic acid," Journal of Applied Electrochemistry, vol. 33, no. 3-4, pp. 233-238, 2003.

[6] A. K. Singh and M. A. Quraishi, "Inhibiting effects of 5substituted isatin-based Mannich bases on the corrosion of mild steel in hydrochloric acid solution," Journal of Applied Electrochemistry, vol. 40, no. 7, pp. 1293-1306, 2010.

[7] N. S. Patel, S. Jauhari, and G. N. Mehta, "The inhibition of mild steel corrosion in $1 \mathrm{~N} \mathrm{HCl}$ by imidazole derivatives," Acta Chimica Slovenica, vol. 57, no. 2, pp. 297-304, 2010.

[8] C. Lee, W. Yang, and R. G. Parr, "Development of the ColleSalvetti correlation-energy formula into a functional of the electron density," Physical Review B, vol. 37, no. 2, pp. 785-789, 1988.

[9] Y. Shao, L. F. Molnar, Y. Jung et al., "Advances in methods and algorithms in a modern quantum chemistry program package," Physical Chemistry Chemical Physics, vol. 8, no. 27, pp. 3172-3191, 2006.

[10] Y. Abboud, A. Abourriche, T. Saffaj et al., "A novel azo dye, 8quinolinol-5-azoantipyrine as corrosion inhibitor for mild steel in acidic media," Desalination, vol. 237 , no. 1-3, pp. 175-189, 2009.

[11] E. E. Ebenso, H. Alemu, S. A. Umoren, and I. B. Obot, "Inhibition of mild steel corrosion in sulphuric acid using Alizarin Yellow GG dye and synergistic iodide additive," International Journal of Electrochemical Science, vol. 3, pp. 1325-1339, 2008.

[12] O. K. Abiola and J. O. E. Otaigbe, "Adsorption Behaviour of 1-phenyl-3-methylpyrazol-5-one on Mild Steel from HCI Solution," International Journal of Electrochemical Science, vol. 3, pp. 191-198, 2008.

[13] A. A. Khadom, A. S. Yaro, A. S. Altaie, and A. A. H. Kadum, "Electrochemical, activations and adsorption studies for the corrosion inhibition of low carbon steel in acidic media," Portugaliae Electrochimica Acta, vol. 27, no. 6, pp. 699-712, 2009.

[14] V. Ramesh Saliyan and A. V. Adhikari, "Inhibition of corrosion of mild steel in acid media by N'-benzylidene-3-(quinolin-4ylthio)propanohydrazide," Bulletin of Materials Science, vol. 31, no. 4, pp. 699-711, 2008.

[15] A. Sharmila, A. A. Prema, and P. A. Sahayaraj, "Influence of Murraya koenigii (curry leaves) extract on the corrosion inhibition of carbon steel in HCL solution," Rasayan Journal of Chemistry, vol. 3, no. 1, pp. 74-81, 2010.

[16] S. Muralidharan, "Effect of piperidones on hydrogen permeation and corrosion inhibition of mild steel in acidic solutions," Proceedings of the Indian Academy of Sciences, vol. 112, no. 2, pp. 127-136, 2000.

[17] G. Y. Elewady, "Pyrimidine derivatives as corrosion inhibitors for carbon-steel in $2 \mathrm{M}$ hydrochloric acid solution," International Journal of Electrochemical Science, vol. 3, pp. 1149-1161, 2008.

[18] E. E. Ebenso, D. A. Isabirye, and N. O. Eddy, "Adsorption and quantum chemical studies on the inhibition potentials of some thiosemicarbazides for the corrosion of mild steel in acidic medium," International Journal of Molecular Sciences, vol. 11, no. 6, pp. 2473-2498, 2010.

[19] N. O. Eddy, S. R. Stoyanov, and E. E. Ebenso, "Fluoroquinolones as corrosion inhibitors for mild steel in acidic medium; Experimental and theoretical studies," International Journal of Electrochemical Science, vol. 5, no. 8, pp. 1127-1150, 2010. 
[20] K. Laarej, M. Bouachrine, S. Radi, S. Kertit, and B. Hammouti, "Quantum chemical studies on the inhibiting effect of bipyrazoles on steel corrosion in HCl," E-Journal of Chemistry, vol. 7, no. 2, pp. 419-424, 2010.

[21] N. O. Obi-Egbedi and I. B. Obot, "Xanthione: A new and effective corrosion inhibitor for mild steel in sulphuric acid solution," Arabian Journal of Chemistry. In press.

[22] N. O. Obi-Egbedi, K. E. Essien, I. B. Obot, and E. E. Ebenso, "1,2-Diaminoanthraquinone as corrosion inhibitor for mild steel in hydrochloric acid: weight loss and quantum chemical study," International Journal of Electrochemical Science, vol. 6, no. 4, pp. 913-930, 2011.

[23] N. O. Eddy and E. E. Ebenso, "Adsorption and quantum chemical studies on cloxacillin and halides for the corrosion of mild steel in acidic medium," International Journal of Electrochemical Science, vol. 5, no. 6, pp. 731-750, 2010. 

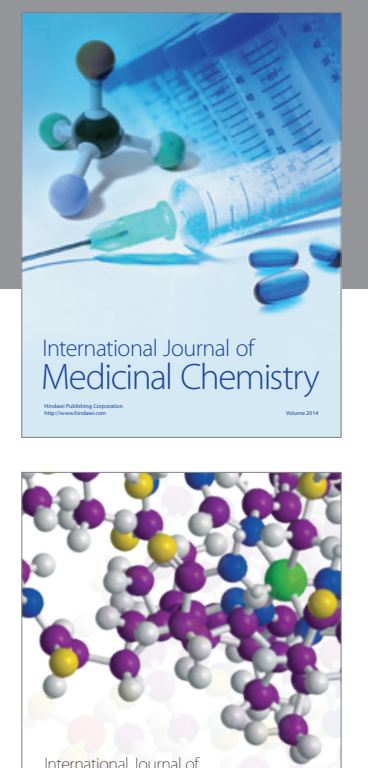

\section{Carbohydrate} Chemistry

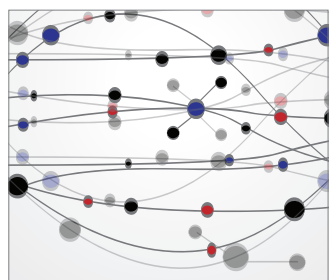

The Scientific World Journal
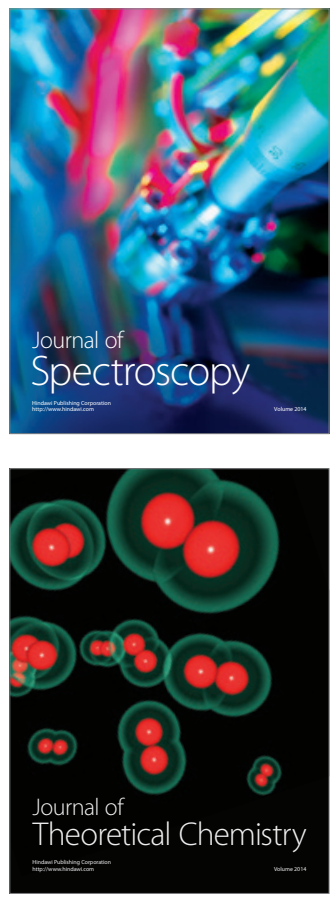
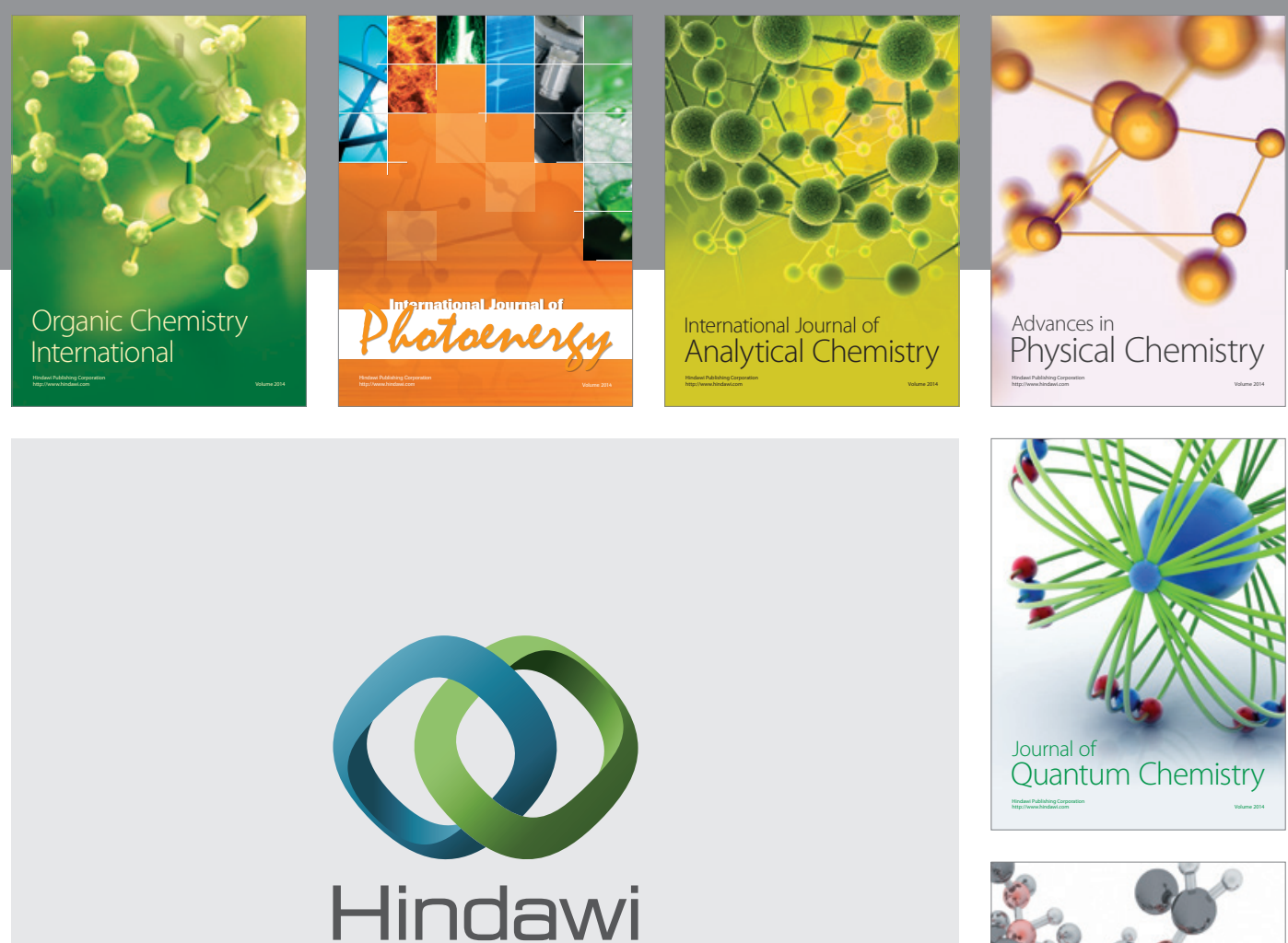

Submit your manuscripts at

http://www.hindawi.com

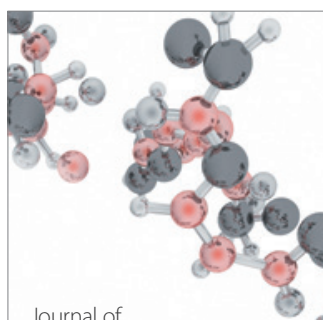

Analytical Methods

in Chemistry

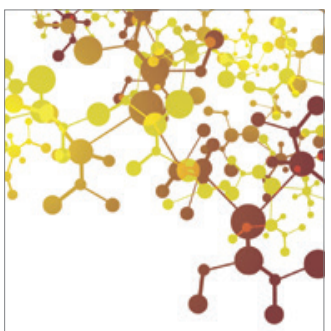

Journal of

Applied Chemistry

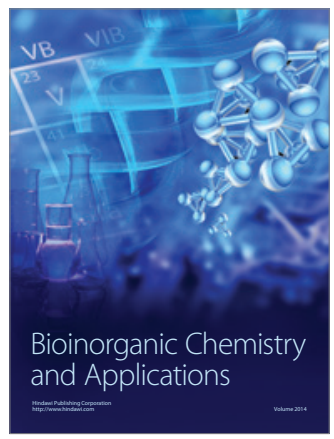

Inorganic Chemistry
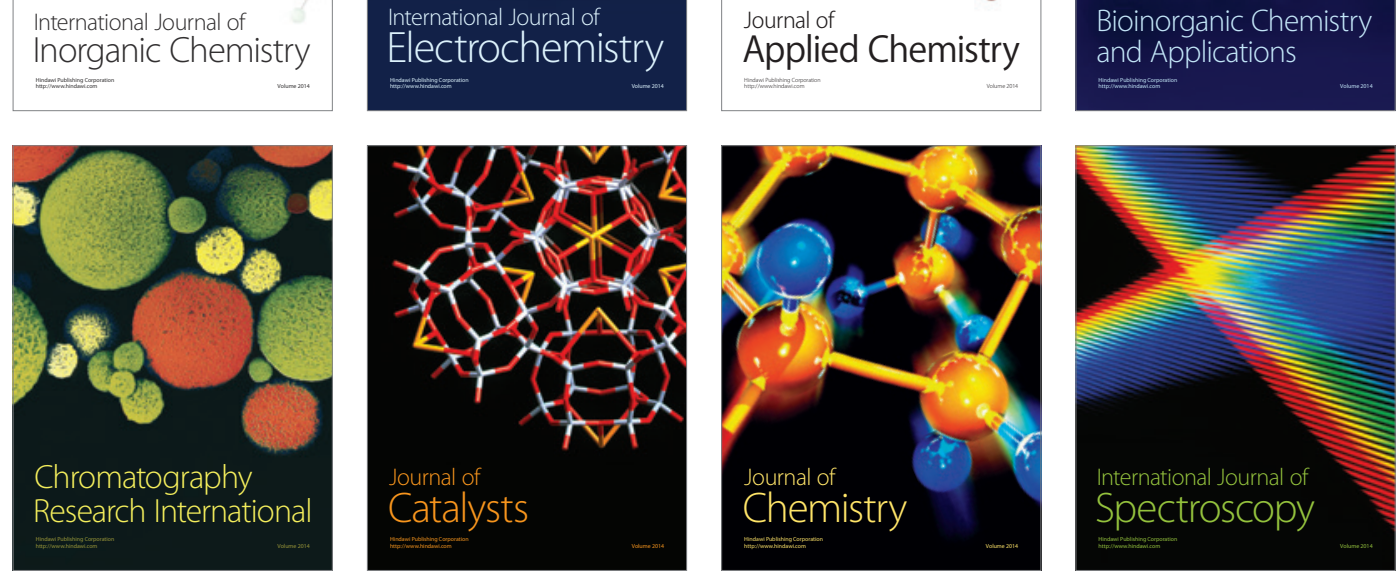